\title{
Pulsed Power Requirements for a High Power KrF Laser Inertial Confinement Fusion Test Facility
}

\author{
J.D. Sethian, S.P. Obenschain, \\ Plasma Physics Division, Naval Research Laboratory, Washingtor, D.C. 20375 \\ M.W. McGeoch \\ PLEX Corporation, 21 Addington Rd, Brookline, MA 02146 \\ I.D. Smith, P.A. Corcoran and R.A. Altes \\ Pulse Sciences, Inc. 600 McCormick St., San Leandro, CA 94577
}

\begin{abstract}
A conceptual design for the pulsed power of a $68 \mathrm{~kJ}$ Krypton Fluoride (KrF) laser amplifier is discussed. The amplifier features double sided electron beam pumping with eight diodes on either side of the laser cell. This amplifier is based on the technology developed for the recently completed Nike laser system. We envision a system in which thirty-two of these amplifiers are combined to produce a $2 \mathrm{MJ}$ KrF laser direct drive inertial confinement test facility.
\end{abstract}

\section{Introduction}

A Krypton-Fluoride (KrF) laser pumped with large area electron beams is a promising candidate for an ICF driver because of its outstanding beam quality, its short wavelength, and straightforward scaling to a large system. The Nike laser at $\mathrm{NRL}^{1}$ is the first step in the development of a KrF ICF driver, and is being used to explore the advantages and limitations of this approach by studying ablatively accelerated planar targets. If experiments with Nike show that the highly uniform laser beam that is unique to $\mathrm{KrF}$ is both necessary and sufficient for high gain, we would recommend the construction of a multi-megajoule KrF facility. (We define high gain as a target that produces greater than 100 times more fusion output energy than the laser input energy). Although this facility would be too large to build at the Naval Research Laboratory, we have produced a conceptual design and cost estimate for it.
The facility consists of 32 amplifiers, each producing $68 \mathrm{~kJ}$ of KrF laser light. For compactness and optical efficiency the $68 \mathrm{~kJ}$ amplifiers are grouped in pairs to produce sixteen $136 \mathrm{~kJ}$ multiplexiad laser lines. With this system we predict a. spherical target will be irradiated with $2.0 \mathrm{MJ}$ of laser light in $7 \mathrm{~ns}$ with a non-uniformity of less than $0.5 \%{ }^{2}$

\section{The 68 kJ Amplifier}

The heart of the $613 \mathrm{~kJ}$ Amplifier is the laser cell that is $3.6 \mathrm{~m}$ long, $1 \mathrm{~m}$ wide and 2.7 $m$ high. The cell is filled with a mixture of krypton, fluorine and an argon buffer. The laser beam enters and exits the cell through a pair of $100 \mathrm{~cm}$ square windows at the $1 \mathrm{mx}$ $2.7 \mathrm{~m}$ ends. Stacking the windows one on top of the other gives an effective aperture of $1 \mathrm{~m} \times 2 \mathrm{~m}$. The laser gas is pumped by injecting electron beams across the laser axis from the opposing $2.7 \mathrm{~m} \times 3.6 \mathrm{~m}$ walls. The electron beams disassociate the krypton and fluorine to create an excited KrF dimer, which then decays back to $\mathrm{Kr}$ and $F_{2}$, producing radiation at $248 \mathrm{~nm}$. The electron beams are produced by sixteen field emission diodes, with each driven by its own parallel plate pulsed power system. Although this amplifier is capable of generating a total of $68 \mathrm{~kJ}$ of laser light, each of the individual diodes in it are actually slightly smaller than the diodes in the final " $60 \mathrm{~cm}$ Amplifier" of the Nike laser. The $60 \mathrm{~cm}$ Amplifier, which produces a laser output of $5 \mathrm{~kJ}$, has been described in detail elsewhere, however it is instructive to 
compare the parameters of the two systems. This is done in the table below:

\begin{tabular}{|l|c|c|}
\cline { 2 - 3 } \multicolumn{1}{c|}{} & $\begin{array}{c}60 \mathrm{~cm} \text { Amplifier } \\
\text { Nike } \\
\text { (existing) }\end{array}$ & $\begin{array}{c}68 \mathrm{~kJ} \text { amplifier } \\
\text { HIGH GAIN } \\
\text { FACILITY } \\
\text { (concept) }\end{array}$ \\
\hline $\begin{array}{l}\text { E-Beam } \\
\text { (flat top) }\end{array}$ & $700 \mathrm{kV}, 500 \mathrm{kA}$ & $800 \mathrm{kV}, 330 \mathrm{kA}$ \\
\hline $\begin{array}{l}\text { PFL stored } \\
\text { energy/diode }\end{array}$ & $90 \mathrm{~kJ}$ & $83 \mathrm{~kJ}$ \\
\hline $\begin{array}{l}\text { Cathode area } \\
\text { (Cathode } \\
\text { current density }\end{array}$ & $200 \mathrm{~cm} \times 60 \mathrm{~cm}$ & $100 \mathrm{~cm} \times 48 \mathrm{~cm}$ \\
\hline $\begin{array}{l}\text { Diodes per } \\
\text { amplifier }\end{array}$ & 2 & $68 \mathrm{Ncm} \mathrm{cm}^{2}$ \\
\hline $\begin{array}{l}\text { Total specific } \\
\text { pump power }\end{array}$ & $350 \mathrm{~kW} / \mathrm{cm}^{3}$ & $800 \mathrm{~kW} / \mathrm{cm}^{3}$ \\
\hline
\end{tabular}

In most cases the parameters of the 68 $\mathrm{kJ}$ amplifier are within $10-20 \%$ of that of the Nike $60 \mathrm{~cm}$ Amplifier. The major difference is the higher specific pump power which is due to both the higher diode power per unit area and an assumed higher energy transmission from cathode into the gas. We achieve the latter by incorporating a new laser cell pressure foil structure based on the "suspension bridge" design conceived and partially tested at Los Alamos". Even though the pump power is higher it is within the parameters that have been achieved in other systems, some of which have operated at over $1 \mathrm{MW} / \mathrm{cm}^{3}$. (In fact, the smaller $20 \mathrm{~cm}$ Amplifier of the Nike laser has operated as high as $550 \mathrm{~kW} / \mathrm{cm}^{3}$.)

Figure 1 shows the view of the $68 \mathrm{~kJ}$ Amplifier from inside the cell, looking into the $\theta$-beam diodes on one side. For comparison, the same view for the Nike $60 \mathrm{~cm}$ Amplifier is shown in the upper portion of the drawing:

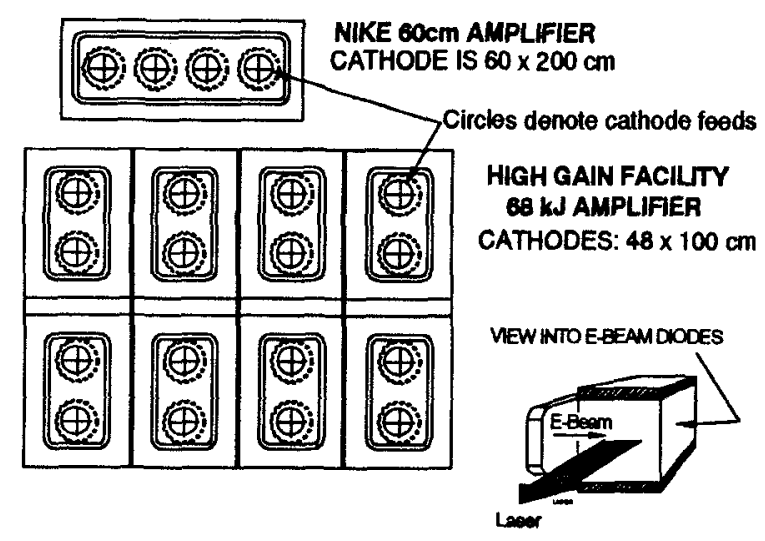

Figure 1: View inside the laser cell, looking into the electron beam diodes for both the proposed 68 $\mathrm{kJ}$ amplifier and the existing Nike $60 \mathrm{~cm}$ amplifier. The diodes along one wall of the cell are shown. An equal number of diodes line the opposite wall.

Figure 2 shows the top view of the cell, as looking down upon the e-beam diodes. It is in this view that the most unique aspect of this $68 \mathrm{~kJ}$ amplifier can be seen: the amplifier is of a "segmented" design, meaning that there are portions of the laser cell that are unpumped (i.e. "missed" by the electron beam). At first glance it was thought that such a design would be severely compromised since the unpumped fluorine, which is a UV absorber, would attenuate so much of the light produced in the pumped regions that the amplifier efficiency would be seriously reduced. However, after carrying out calculations with an experimentally tested KrF amplifier model ${ }^{6}$, it was determined that this is not the case as the reduction in Amplified Stimulated Emission from the segmentation compensates for the absorption. In addition to laser considerations, such a design allows significant simplification in the pulsed power: 1) the electron beams can be guided in the standard fashion with a simple parallel magnetic field; 2) because the diodes can now be surrounded with return current planes on all four sides, the self field is reduced, the guide field can be relatively low, and the diode closure is reduced; and finally 3 ), the 
return current planes reduce the system inductance and hence relax the requirements on the pulsed power.

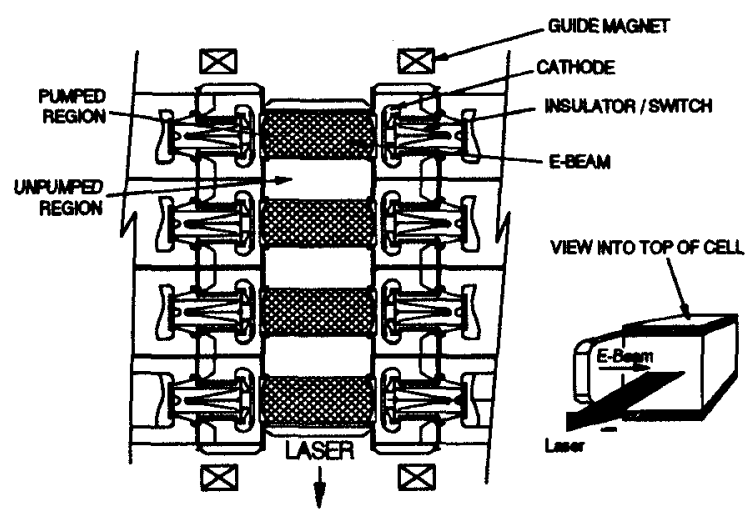

Figure 2: Top view of the $68 \mathrm{~kJ}$ amplifier showing the diodes, insulator/switch assemblies and the guide magnet. Note the "unpumped" regions.

The end view of the laser cell, looking along the path of the laser beam, is shown in Figure 3. This view clearly shows the two $100 \mathrm{~cm} \times 100 \mathrm{~cm}$ optical windows that make up the effective optical aperture of $100 \mathrm{~cm} \mathrm{x}$ $200 \mathrm{~cm}$. Note that comparing Figures 2 and 3 shows the cell is pumped by sixteen separate electron beam diodes.

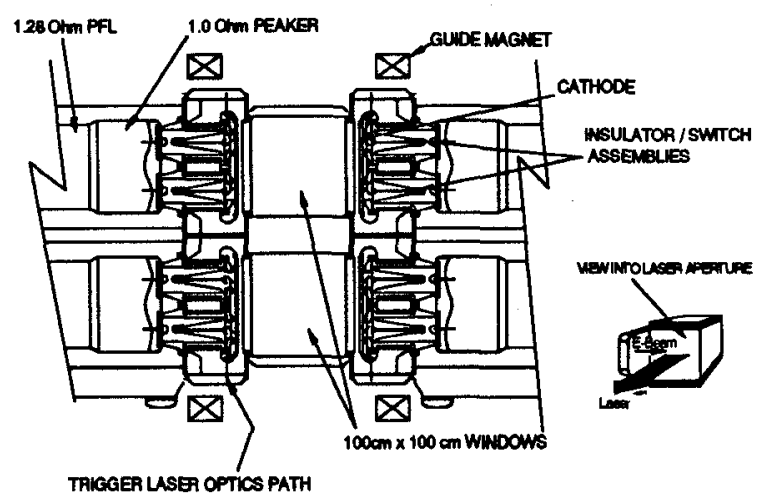

Figure 3: End view of the laser cell.

One of the features of this design is that each diode is connected to its own pulse line through two monolithic vacuum insulator sections that contain both the $\mathrm{SF}_{6}$-insulated switch and the insulating gas around the cathode stalk. The details of this are shown below in Figure 4. The plastic insulator body is fabricated by casting and/or machining a single piece onto which split metal grading rings are pressed. This arrangement is considerably less expensive than the conventional one in which the switch is located in a separate housing and the insulators and grading rings are individual components that are stacked and held together by external tir rods. This design also substantially decreases the inductance.

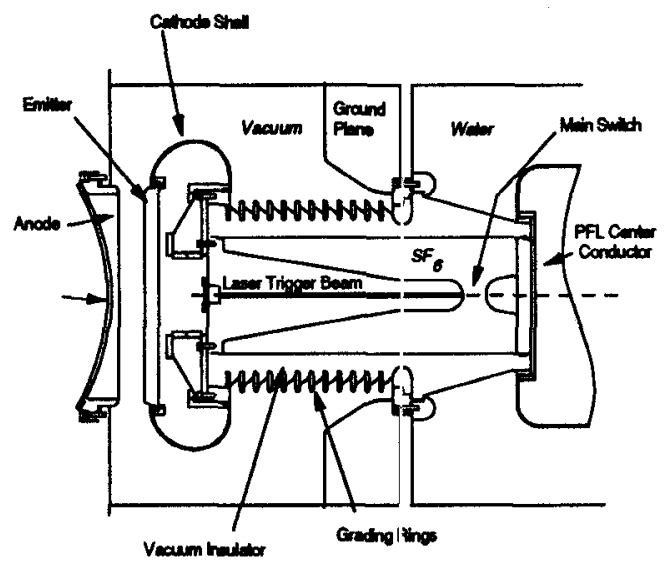

Figure 4: Top view of the integrated switch/insulator stack section. There are two of these per cathode.

Although mechanically unconventional, potential plots both before and after switching show that the insulator is graded quite uniformly and the average field is well below the threshold for breakdown.

Each pair of switcles (and hence each diode) is fed by a water dielectric rectangular cross section pulse forming line (PFL) of depth $1 \mathrm{~m}$ (to correspond the cathode dimension), width $55 \mathrm{~cm}$, and length $5 \mathrm{~m}$ (corresponding to a pulse duration of 300 nsec and a flat top disration of 250 nsec). The PFLs are charged to $1.64 \mathrm{MV}$ in $1.8 \mu \mathrm{s}$ by a Marx bank. One Marx charges four PFLs. Each Marx has eleven stages, with two $3.0 \mu \mathrm{F}$ capacitors per stage and each stage charged to $\pm 90 \mathrm{kV}$.

We have simulated the pulsed power behavior of this amplifier, assuming the anode cathode gap hasi an initial value of $\mathbf{5 . 5}$ 
$\mathrm{cm}$ and a closure velocity of $2.3 \mathrm{~cm} / \mu \mathrm{sec}$. Best results are obtained if we assume the diode is driven by a 130 nsec, $1.28 \Omega$ pulseline followed with a 20 ns long $1 \Omega$ peaker section at the output end of Figure 3. This is very similar to the successful arrangement of the Nike $60 \mathrm{~cm}$ Amplifier. ${ }^{3}$ We found that if the output switches are fired at near peak charge on the waterline, the diode voltage ramps down and the current ramps up by about $6 \%$, averaging $790 \mathrm{kV}$ and $690 \mathrm{kA}$, respectively, throughout the top part of the pulse. The power to the diode remains almost constant at $54.5 \mathrm{TW} \pm 2 \%$. This is more than adequate to meet the laser uniformity requirements.

As said at the outset, we have designed and estimated the cost of an entire $2 \mathrm{MJ}$ laser facility. As part of that effort, we determined that the cost to develop the pulsed power for the $68 \mathrm{~kJ}$ amplifier comes out to $\$ 20 \mathrm{M}$ for the first unit, where we have allowed a $25 \%$ contingency. The cost reduces to about $\$ 7.1 \mathrm{M}$ in a quantity of 32 for the $2 \mathrm{MJ}$ laser facility. Part of the savings is in the "learning" applied when building a large number of units, and part is due to the fact that a lot of the amplifier subsystems (i.e. gas handling, gas recovery, control systems) would be shared with other components of the facility. The entire cost of the $2 \mathrm{MJ}$ laser facility, including target chamber, all support services, and a $25 \%$ contingency, has been estimated to be $\$ 950 \mathrm{M}$. These numbers were obtained with the same algorithms used in costing previous LMF designs ${ }^{7}$, the $\mathrm{NIF}^{8}$, and other large pulsed power systems, ${ }^{9}$ as well as experience in building the Nike laser.

The first step in building the $2 \mathrm{MJ}$ facility would be to construct a $68 \mathrm{~kJ}$ module. We believe that this represents the major risk in the development of the $2 \mathrm{MJ}$ facility. Taken individually, none of the parameters of the 68 $\mathrm{kJ}$ amplifier represent a significant extension of the Nike $60 \mathrm{~cm}$ Amplifier, but as a whole the amplifier represents a factor of ten increase in laser output energy. After developing the pulsed power for the $68 \mathrm{~kJ}$ system, the next step would be to develop it into a laser amplifier. This would involve adding a front end, driver amplifier, and multiplexing/ demultiplexing optics. If these tests were successful, we would be confident that we could design the entire facility.

* Work supported by U.S. Department of Energy

1. S.P. Obenschain, S.E. Bodner, D. Colombant, K. Gerber, R.H. Lehmberg, E.A. McLean, A. N. Mostovych, M.S. Pronko, C.J. Pawley, A.J. Schmitt, J.D. Sethian, V. Serlin, J.A. Stamper, C.A. Sullivan, J.P. Dahiburg, J.H. Gardner, Y. Chan, A.V. Deniz, J. Hardgrove, T. Lehecka, and M. Klapisch, "The Nike Krf Laser Facility; Performance And Initial Target Experiments," Physics of Plasmas, 3, 2098 (1996).

2. M.W. McGeoch, P.A. Corcoran, R.G. Altes, I.D. Smith, S.E. Bodner, R.H. Lehmberg, S.P. Obenschain and J.D. Sethian, "Conceptual Design Of A 2 MJ KrF Laser Fusion Facility", to be published.

3. J.D. Sethian, C.J. Pawley, S.P. Obenschain, K.A. Gerber, and V. Serlin, T. Lehecka, W. D. Webster, I.D. Smith, P.A. Corcoran and A.A. Altes, "The Nike Electron Beam-Pumped KrF Amplifiers," Presented at the Tenth IEEE Pulsed Power Conference, held in Albuquerque, NM July 10-13, 1995.

4. G. York, "An Advanced Electron Beam HibachiDesign And Performance," Proceedings $4^{\text {th }}$ International Workshop on KrF Laser Technology, Annapolis MD, (1994).

5. C. J. Pawley, "Measurements of Electron Beam Pumping and Gain" ibid. ref. 4.

6. M. W. McGeoch, "A Simplified KrF Kinetics Model", ibid. ref. 4. Also, M.W. McGeoch, "Time Dependent Amplifier with Kinetics and ASE", ibid. ref. 4.

7. "Laboratory Microfusion Capability Cost Study" Bechtel Corporation (U.S. Department of Energy, August 1991).

8. "Manufacturing Readiness Plan for the National Ignition Facility" Lawrence Livermore National Laboratory Report NIF-LLNL-94-204 (April 1994).

9. D.B. Harris, J.A. Sullivan, N.A. Kurnit, E.A. Rose and J.M. McLeod, "KrF Laser-Driven Laboratory Microfusion Facility", Report LA-UR-91-2915, Los Alamos National Laboratory, Dec. 1991. 